\title{
Lusisersily
}

\section{Mixing Behavior of the Biosurfactant, Rhamnolipid, with a Conventional Anionic Surfactant, Sodium Dodecyl Benzene Sulfonate}

Chen, ML., Penfold, J., Thomas, RK., Smyth, TJP., Perfumo, A., Marchant, R., Banat, IM., Stevenson, P., Parry, A., Tucker, I., \& Grillo, I. (2010). Mixing Behavior of the Biosurfactant, Rhamnolipid, with a Conventional Anionic Surfactant, Sodium Dodecyl Benzene Sulfonate. Langmuir, 26(23), 17958-17968.

Link to publication record in Ulster University Research Portal

Published in:

Langmuir

Publication Status:

Published (in print/issue): 01/01/2010

\section{Document Version}

Publisher's PDF, also known as Version of record

\section{General rights}

Copyright for the publications made accessible via Ulster University's Research Portal is retained by the author(s) and / or other copyright owners and it is a condition of accessing these publications that users recognise and abide by the legal requirements associated with these rights.

\section{Take down policy}

The Research Portal is Ulster University's institutional repository that provides access to Ulster's research outputs. Every effort has been made to ensure that content in the Research Portal does not infringe any person's rights, or applicable UK laws. If you discover content in the Research Portal that you believe breaches copyright or violates any law, please contact pure-support@ulster.ac.uk. 


\title{
Langmuir
}

pubs.acs.org/Langmuir

(C) 2010 American Chemical Society

\section{Mixing Behavior of the Biosurfactant, Rhamnolipid, with a Conventional Anionic Surfactant, Sodium Dodecyl Benzene Sulfonate}

\author{
M. L. Chen ${ }^{\dagger}$ J. Penfold $,{ }^{*}, \dagger, \star$ R. K. Thomas,${ }^{\dagger}$ T. J. P. Smyth,${ }^{\S}$ A. Perfumo,${ }^{\S}$ R. Marchant,${ }^{\S}$ \\ I. M. Banat, ${ }^{\S}$ P. Stevenson," A. Parry," I. Tucker," and I. Grillo ${ }^{\perp}$ \\ ${ }^{\dagger}$ Physical and Theoretical Chemistry Department, University of Oxford, South Parks Road, Oxford, \\ United Kingdom, ${ }^{*} S T F C$, Rutherford Appleton Laboratory, Chilton, Didcot, OXON, United Kingdom, \\ ${ }^{\S}$ School of Biomedical Sciences, University of Ulster, Coleraine, Northern Ireland, United Kingdom, \\ Unilever Research and Development Laboratory, Port Sunlight, Wirral, United Kingdom, and \\ ${ }^{\perp}$ Institute Laue Langevin, 6 rue Jules Horowitz, F-38042, Grenoble, Cedex 09, France
}

Received August 10, 2010. Revised Manuscript Received October 15, 2010

\begin{abstract}
The use of small angle neutron scattering, SANS, neutron reflectivity, NR, and surface tension to study the mixing properties of the biosurfactant rhamnolipid with a conventional anionic surfactant, sodium dodecyl 6-benzene sulfonate, LAS, is reported. The monorhamnose rhamnolipid, R1, mixes close to ideally with LAS at the air-water interface, whereas for mixtures of LAS with the dirhamnose rhamnolipid, R2, the LAS strongly partitions to the air-water interface relative to R2, probably because of the steric hindrance of the larger R2 headgroup. These trends in the binary mixtures are also reflected in the ternary R1/R2/LAS mixtures. However, for these ternary mixtures, there is also a pronounced synergy in the total adsorption, which reaches a maximum for a LAS/rhamnolipid mole ratio of about 0.6 and a R1/R2 mol ratio of about 0.5 , an effect which is not observed in the binary mixtures. In solution, the $\mathrm{R} 1 / \mathrm{LAS}$ mixtures form relatively small globular micelles, $\mathrm{L}_{1}$, at low surfactant concentrations $(<20 \mathrm{mM})$, more planar structures (lamellar, $\mathrm{L}_{\alpha}$, unilamellar/multilamellar vesicles, ulv $/ \mathrm{mlv}$ ) are formed at higher surfactant concentrations for R1 and LAS rich compositions, and a large mixed phase $\left(\mathrm{L}_{\alpha} / \mathrm{L}_{1}\right.$ and $\left.\mathrm{L}_{1} / \mathrm{L}_{\alpha}\right)$ region forms at intermediate surfactant compositions. In contrast, for the R2/LAS mixtures, the higher preferred curvature of R2 dominates the phase behavior. The predominant microstructure is in the form of small globular micelles, except for solution compositions rich in LAS ( $>80 \mathrm{~mol} \% \mathrm{LAS}$ ) where more planar structures are formed. For the ternary mixtures, there is an evolution in the resulting phase behavior from one dominated by $\mathrm{L}_{1}\left(\mathrm{R} 2\right.$ rich) to one dominated by planar structures, $\mathrm{L}_{\alpha},(\mathrm{R} 1$, LAS rich), and which strongly depends upon the $\mathrm{LAS} /$ rhamnolipid and $\mathrm{R} 1 / \mathrm{R} 2$ mole ratio.
\end{abstract}

\section{Introduction}

There is an increasing interest in the study of biosurfactants because of their potential for exploitation in a wide range of diverse products that are biosustainable and biodegradable. ${ }^{1}$ They are being applied to or considered for an increasingly wide range of applications, which include enhanced oil recovery, ${ }^{2}$ bioremediation, ${ }^{3}$ and some specialized healthcare and cosmetic applications which particularly exploit their antimicrobial and/or antifungal properties. ${ }^{4} \mathrm{~A}$ wide variety of different types of biosurfactant are synthesized by many different micro-organisms. One of the more commonly studied categories is the glycolipids, ${ }^{5}$ such as the rhamnolipids, sophorolipids, and trehalolipids. The glycolipids are dissacharides that are aceylated by long chain fatty acids. Compared with conventional surfactants, they have lower toxicity, higher biogradability, and higher tolerance to $\mathrm{pH}$, temperature, and salinity, and can be synthesized from a variety of nonpetrochemical based sources. Although the rhamnolipids are one of the more extensively utilized and studied biosurfactants, ${ }^{6}$ the greater difficulty of large scale production and purification compared with conventional surfactants has hindered their wider

(1) Muthusamy, K; Gopalakrishnan, S; Kockupappy, T; Sivachidambaram, P Curr. Sci. 2008, 94, 736.

(2) Banat, I. M.; Mukkar, R. S.; Cameotra, S. S. Appl. Microbiol. Biotechnol. 2000, 53, 495 .

(3) Mulligan, C. N. Environ. Pollut. 2005, 133, 183.

(4) Desai, J. D.; Banat, I. M. Microbiol and Mol Biol Rev 1997, 61, 47.

(5) Georgiou, G.; Liu, S. S.; Sharma, M. M. Biotechnology 1992, 10, 60.

(6) Nitschke, M; Costa, S. G. V. A. O.; Contiero, J. Biotechnol. Prog. 2005, 21, 1693.

(7) Guo, Y. P.; Hu, Y. Y.; Cu, R. R.; Lin, H. J. Colloid Interface Sci. 2009, 331, exploitation. Although there has been a number of studies ${ }^{7-12}$ this wider exploitation is further hindered by a lack of fundamental physicochemical characterization of biosurfactant properties and especially of mixtures of biosurfactants with conventional surfactants.

The rhamnolipids are rhamnose containing glycolipid surfactants, which are produced by different strains of the bacteria Pseudomonas aeruginosa. ${ }^{2}$ They generally exist as one or two molecules of rhamnose linked to one or two molecules of $\beta$-hydroxydecanoic acid. The most common forms and major components are L-rhamnosyl-L-rhamnosyl- $\beta$-hydroxydecanoyl$\beta$-hydroxydecanoate (Rha $2 \mathrm{C}_{10} \mathrm{C}_{10}, \mathrm{R} 2$ ) and L-rhamnosyl$\beta$-hydroxydecanoyl- $\beta$-hydroxydecanoate $\left(\mathrm{RhaC}_{10} \mathrm{C}_{10}, \mathrm{R} 1\right)$. In practice, a variety of other components (as minority components), of different alkyl chain length combinations, which depend upon carbon source and bacterial strain, exist. A number of recent publications have reported details of rhamnolipid production, purification, and characterization. ${ }^{7,8,11,13}$ They have addressed different aspects of rhamnolipid surface adsorption and selfassembly, using predominantly surface tension measurements and some limited X-ray, light, and neutron scattering studies.

(8) Abalos, A.; Pinazo, A.; Infante, M. R.; Casals, M.; Garcia, F.; Manresa, A. Langmuir 2001, 17, 1367.

(9) Helvaci, S. S.; Peker, S.; Ozdemir, G. Colloids Surf., B 2004, 35, 225.

(10) Ozdemir, G.; Peker, S.; Helvaci, S. S. Colloids Surf., A 2004, 234, 135.

(11) Sanchez, M.; Aranda, F. J.; Espuny, M. J.; Marques, A.; Teruel, J. A.; Manresa, A.; Ortiz, A. J. Colloid Interface Sci. 2007, 307, 246.

(12) Dahrazma, B.; Mulligen, C. N.; Nieh, M. P. J. Colloid Interface Sci. 2008, 319,590 .

(13) Smyth, T. J.; Perfumo, A.; Marchant, R.; Chen, M. L.; Thomas, R. K.; Penfold, J.; Banat, I. M. Appl. Microbiol. Biotechnol. 2010, 87, 1347. 
More recently, we ${ }^{14}$ have used neutron reflectivity (NR), small angle neurton scattering (SANS), and surface tension to investigate in some detail the surface adsorption and solution selfassembly of the rhamnolipids R1 and R2, and their mixtures. At the air-water interface, R1 and R2 exhibit Langmuir-like adsorption isotherms, where $\mathrm{R} 1$ is more surface active than $\mathrm{R} 2$. In $\mathrm{R} 1 / \mathrm{R} 2$ mixtures, there is a stronger partitioning of $\mathrm{R} 1$ to the surface than would be expected from their relative surface activities. R2 competes less favorably due to the packing constraints associated with the bulkier R2 headgroup, analogous to the behavior reported for the nonionic surfactant mixture of $\mathrm{C}_{12} \mathrm{E}_{3} / \mathrm{C}_{12} \mathrm{E}_{8}{ }^{15,16}$ In solution, R1 and R2 both form small globular micelles in dilute solution. At higher surfactant concentrations, R1 transforms to predominantly planar structures (lamellar, $\mathrm{L}_{\alpha}$, or unilamellar/bilamellar vesicles, ulv/blv) whereas $\mathrm{R} 2$ remains as globular micelles. In $\mathrm{R} 1 / \mathrm{R} 2$ mixtures, solutions rich in $\mathrm{R} 2$ are predominantly micellar and those rich in $\mathrm{R} 1$ have predominantly planar structures. At intermediate R1/R2 compositions, lamellar/micellar coexistence exists, but the higher curvature associated with $\mathrm{R} 2$ dominates the R1/R2 mixing behavior.

The diverse range of applications of surfactants, such as home and personal care products, usually involve mixtures of different surfactants. ${ }^{17,18}$ This is because mixtures provide a synergistic enhancement of many aspects of performance and functionality, which gives greater flexibility for processing and formulation, and because many commercially used surfactants are inherently mixtures. In recent years, modern analysis techniques, but especially neutron scattering (NR and SANS) in combination with $\mathrm{D} /$ $\mathrm{H}$ isotopic substitution, have provided the experimental tools to enable substantial advances in our ability to probe surfactant mixing at interfaces and in solution. ${ }^{19}$ This has considerably advanced our understanding of the behavior of mixed surfactants in a wide range of systems and conditions. ${ }^{19}$

In the immediate future, the most effective exploitation of biosurfactants is likely to be as mixtures with conventional surfactants. Hence, there is a strong and urgent need to understand the fundamental properties of biosurfactants mixed with conventional surfactants, and that is the focus of this paper. We report here the use of surface tension, NR, and SANS to study the surface adsorption and solution self-assembly of R1/LAS, R2/ LAS, and R1/R2/LAS mixtures over a wide range of solution compositions and concentrations.

\section{Experimental Details}

i. Materials. The hydrogeneous rhamnolipids were obtained from Jeneil Biosurfactant Co. and separated into the pure R1 and $\mathrm{R} 2$ components (abbreviated as h-R1, h-R2) as described previously ${ }^{14}$ The deuterated rhamnolipids were grown in a Pseudomonas aeruginosa culture and fed with $\mathrm{D}_{2} \mathrm{O}$ and d-glycerol, and the procedure for production and initial extraction and purification is described in detail elsewhere. ${ }^{13}$ The pure R1 and R2 components (abbreviated as d-R1, d-R2) were separated and characterized as described in detail elsewhere ${ }^{14}$ and were $\sim 90 \%$ deuterated. The sodium 6-dodecyl benzene-4 sulfate, LAS (6-phenyl isomer), was

(14) Chen, M. L ; Penfold, J · Thomas, R. K.; Smyth, T. J. P ; Perfumo, A ; Marchant, R.; Banat, I. M.; Stevenson, P.; Parry, A.; Tucker, I.; Grillo, I. Langmuir 2010 DOI: 10.1021\la1031812.

(15) Penfold, J.; Staples, E.; Thompson, L.; Tucker, I. Colloids Surf., A 1995, $102,127$.

(16) Penfold, J.; Staples, E.; Tucker, I.; Thomas, R. K.; Woodling, R.; Dong, C. C. J. Colloid Interface Sci. 2003, 262, 235.

(17) Scamehorn, J. F., Ed. Phenomena in mixed surfactant systems; ACS Symposium Series; American Chemical Society: Washington, DC, 1986; Vol. 311.

(18) Ogino, K., Abe, M., Eds. Mixed surfactant systems; Surfactant Science Series; Marcel Dekker: New York, 1993; Vol. 46.

(19) Lu, J. R.; Thomas, R. K.; Penfold, J. Adv. Colloid Interface Sci. 2000, $84,143$. synthesized and used in two forms, with and without the dodecyl chains and phenyl rings deuterium labeled (d-LAS, h-LAS). The preparation, purification, and characterization of the LAS is described in detail elsewhere. ${ }^{20}$

The aqueous solutions of the rhamnolipid/LAS mixtures were prepared by molar concentration in UHQ water (for the surface tension measurements), in $\mathrm{D}_{2} \mathrm{O}$ (for the SANS measurements), and in null reflecting water (nrw, a $92 \mathrm{~mol} \% \mathrm{H}_{2} \mathrm{O} / 8 \mathrm{~mol} \% \mathrm{D}_{2} \mathrm{O}$ mixture, for the NR measurements and also in $\mathrm{D}_{2} \mathrm{O}$ for some of the structural NR measurements). The surface tension, NR, and SANS measurements were all made at $\mathrm{pH}$ 9. The $\mathrm{pH} 9$ buffer consisted of $0.023 \mathrm{M}$ borax and $0.008 \mathrm{M} \mathrm{HCl}$.

ii. Surface Tension. The surface tension measurements were made using a Kruss K10 maximum pull tensiometer with a Pt/Ir $\mathrm{du}$ Nouy ring. The tensiometer was calibrated by measurements in pure water before each set of measurements. The measurements were carried out at $30^{\circ} \mathrm{C}$ and were made after dipping the $\mathrm{Pt} / \mathrm{Ir}$ ring in the solution and keeping at the surface for $15 \mathrm{~min}$ to establish equilibrium conditions. The average of three repeated measurements was taken, and the experimental deviation was of order $\pm 0.5 \mathrm{mN} \mathrm{m}^{-1}$. The $\mathrm{Pt} / \mathrm{Ir}$ ring and all associated glassware were washed in chromic acid, deionized water, and acetone. In addition, the platinum ring was flamed immediately before use.

iii. Neutron Reflectivity. The neutron reflectivity measurements were made on the SURF reflectometer at the ISIS pulsed neutron source. ${ }^{21}$ The measurements were made using a single detector at a fixed angle, $\theta$, of $1.5^{\circ}$ and for neutron wavelengths, $\lambda$, in the range $0.5-6.8 \AA$ to provide a wave vector transfer, $Q(Q=$ $(4 \pi / \lambda) \sin \theta$, where $\theta$ is the grazing angle of incidence), range of $0.048-0.5 \AA^{-1}$. The absolute reflectivity was calibrated with respect to the reflectivity of $\mathrm{D}_{2} \mathrm{O}$, and the background determined from the reflectivity at the limit of high $Q$, using now well-established experimental procedures. ${ }^{22}$ In the kinematic approximation, ${ }^{19}$ the specular reflectivity is related to the square of the Fourier transform of the scattering length density profile, $\rho(z)$,

$$
R(Q)=\frac{16 \pi^{2}}{Q^{2}}\left|\int \rho(z) \mathrm{e}^{-i Q z} \mathrm{~d} z\right|^{2}
$$

where $r(z)=\Sigma_{i} n_{i}(z) b_{i}, n_{i}(z)$ is the number density of the $i$ th nucleus at a distance of $z$ from the interface, and $b_{i}$ is its scattering length. Application of this technique to the study of surfactant adsorption relies on the ability to manipulate $\rho(z)$ by hydrogen/deuterium $(\mathrm{H} / \mathrm{D})$ isotopic substitution, and this has been extensively exploited at the air-water interface for a range of surfactants and mixed surfactants. ${ }^{19}$ Analysis of the reflectivity data proceeds using eq 1 or the more complete optical matrix method ${ }^{19}$ to calculate the reflectivity from appropriate models.

iv. SANS. The SANS measurements were made on the D11 and D22 diffractometers at the ILL, France ${ }^{23}$ and on the LOQ diffractometer at ISIS, U.K. ${ }^{24}$ On D22, the measurements were made at a neutron wavelength, $\lambda$, of $8 \AA$, a $\Delta \lambda / \lambda$ of $10 \%$, and two different sample to detector distances, 3.5 and $16.5 \mathrm{~m}$, to cover a scattering vector, $Q$, range of $0.002-0.2 \AA^{-1}$ (where the scattering vector, $Q$, is defined as $Q=4 \pi / \lambda \sin (\theta / 2)$, and $\theta$ is the scattering angle). The D11 measurements were made at a neutron wavelength, $\lambda$, of $6 \AA$, a $\Delta \lambda / \lambda$ of $10 \%$, and three sample to detector distances, $1.1,5.0$, and $16.5 \mathrm{~m}$, to cover a scattering vector, $Q$, range of $0.003-0.25 \AA^{-1}$. On LOQ, the measurements were made

(20) Penfold, J.; Thomas, R. K.; Dong, C. C.; Tucker, I.; Metcalfe, K.; Golding, S.; Grillo, I. Langmuir 2007, 23, 10140.

(21) Penfold, J.; Ricjhardson, R. M.; Zarbakhsh, A.; Webster, J. R. P.; Bucknall, D. G.; Rennie, A. R.; Jones, R. A. L.; Cosgrove, T.; Thomas, R. K.; Higgins, J. S.; Fletcher, P. D. I.; Dickinson, E.; Roser, S. J.; McLure, I. A.; Hillman, A. R.; Richards, R. W.; Staples, E. J.; Burgess, A. N.; Simister, E. A.; White, J. W. J. Chem. Soc., Faraday Trans. 1997, 93, 3800.

(22) Lee, E. M.; Thomas, R. K.; Ward, R. C. J. Phys. Chem. 1989, 93, 381

(23) Neutron beam facilities at the high flux reactor available to users, ILL, Grenoble, France, 1994

(24) Heenan, R. K.; King, S. M.; Penfold, J. J. Appl. Crystallogr. 1997, 30, 1140. 
using the white beam time-of-flight method, using neutron wavelengths in the range $2-10 \AA$ and a sample to detector distance of $4 \mathrm{~m}$ to cover a $Q$ range of $0.008-0.25 \AA^{-1}$. All the LOQ measurements were made with a $8 \mathrm{~mm}$ diameter beam, and on D11 and D22 using a beam of $7 \times 10 \mathrm{~mm}$. The data were corrected for background scatter, detector response, and spectral distribution of the incident beam (for LOQ) and converted to an absolute scattering cross section, $\mathrm{d} \sigma / \mathrm{d} \Omega\left(\right.$ in $\mathrm{cm}^{-1}$ ), using standard procedures. ${ }^{25,26}$

The form of the SANS scattering patterns ( $Q$ dependence) was used qualitatively to identify the lamellar (vesicle), micellar, and mixed phase regions of the overall phase behavior. In the purely micellar regions, a detailed quantitative analysis was also made using standard modeling procedures for mixed surfactant micelles ${ }^{27}$ adapted for the rhamnolipid/LAS mixtures.

The scattering from globular surfactant micelles in aqueous solution is described by the "decoupling approximation", derived by Hayter and Penfold, ${ }^{27}$ such that,

$$
\frac{\mathrm{d} \sigma}{\mathrm{d} \Omega}=n\left[S(Q)\left|\langle F(Q)\rangle_{Q}\right|^{2}+\left\langle|F(Q)|^{2}\right\rangle_{Q}-\left|\langle F(Q)\rangle_{Q}\right|^{2}\right]
$$

where the averages denoted by $\langle Q\rangle$ are averages over particles size and orientation, $n$ is the micelle number density, $S(Q)$ is the intermicellar structure factor, and $F(Q)$ is the micelle form factor. The micelle structure (form factor, $F(Q)$ ) is modeled using a standard "core and shell" model, ${ }^{24}$ where the form factor for globular micelles is

$$
F(Q)=V_{1}\left(\rho_{1}-\rho_{2}\right) F_{0}\left(Q r_{1}\right)+V_{2}\left(\rho_{2}-\rho_{\mathrm{s}}\right) F_{0}\left(Q r_{2}\right)
$$

and $r_{1}, r_{2}$ are the core and shell radii, $V_{i}=4 \pi r_{i}^{3} / 3$,

$$
F_{0}\left(Q R_{i}\right)=3 j_{1}\left(Q r_{i}\right) /(Q r)=3[\sin (Q r)-Q r \cos (Q r)] /(Q r)^{3}
$$

$\rho_{1}, \rho_{2}$, and $\rho_{\mathrm{s}}$ are the scattering length densities of the micelle core shell and of the solvent, and $j_{1}\left(Q r_{\mathrm{i}}\right)$ is a first order spherical Bessel function. The "decoupling approximation" assumes that for interacting (finite $S(Q)$ ) globular micelles there is no correlation between position, size, and orientation. The structure factor, $S(Q)$, which quantifies the intermicellar interactions/correlations, is included using the rescaled mean spherical approximation, RMSA, calculation ${ }^{28,29}$ for a repulsive screened Coulombic intermicellar interaction potential, characterized by the surface charge of the micelle, $z$, the Debye-Huckel inverse screening length, $\kappa_{\mathrm{dh}}$ (defined in the usual way), and the micelle number density, $n$.

v. Light Scattering. Dynamic light scattering, DLS, measurements were made using a Malvern PCS8/4700 instrument and $7132 \mathrm{~A}$ correlator. Data were collected in triplicate with run times of $120 \mathrm{~s}$ and the individual autocorrelation functions obtained were analyzed using the Contin method to obtain the particle size distributions. ${ }^{30}$ The light scattering measurements were used predominantly to reinforce the identification of the mixed lamellar/ micellar phase regions, and were particularly sensitive to small levels of the larger lamellar (vesicle) component.

\section{Results and Discussion}

i. Surface Tension. Surface tension measurements were made for R1, R2, LAS, and R1/LAS and R2/LAS mixtures (at solution compositions of rhamnolipid/LAS mole ratio of 30/70, 50/50, 70/ 30) at $\mathrm{pH} 9$ in buffer, as described in the experimental section. The surface tension data for R1/LAS are illustrated in Figure 1 in the Supporting Information and are typical of the measurements made.

(25) Ghosh, R. E.; Egelhaaf, S.; Rennie, A. R. ILL Int. Rep. 1998, ILL98GH14T (26) Heenan, R. K.; King, S. M.; Osborn, R.; Stanley, H. B. RAL Int. Rep. 1989, RAL-98-128.

(27) Hayter, J. B.; Penfold, J. Colloid Polym. Sci. 1983, 261, 1072.

(28) Hayter, J. B.; Penfold, J. Mol. Phys. 1981, 41, 109

(29) Hayter, J. B.; Hansen, J. P. Mol. Phys. 1982, 42, 651.

(30) Provencher, S. W. Makromol. Chem. 1979, 180, 201.
Table 1. Surface Tension Parameters for R1, R2, LAS, and R1/LAS (at 30/70, 50/50, and 70/30 Mole Ratios)

\begin{tabular}{lccc}
\hline \multicolumn{1}{c}{ system } & $\begin{array}{c}\text { CMC } \\
( \pm 0.02 \mathrm{mM})\end{array}$ & $\begin{array}{c}\text { surface tension, } \\
( \pm 0.2 \mathrm{mN} / \mathrm{m}) \\
\text { at CMC }\end{array}$ & $\begin{array}{c}\text { surface excess, } \\
\Gamma( \pm 0.2 \times \\
\left.10^{-10} \mathrm{~mol} \mathrm{~cm}^{-2}\right)\end{array}$ \\
\hline $\mathrm{R} 1$ & 0.36 & 31.2 & 2.2 \\
$\mathrm{R} 2$ & 0.18 & 37.4 & 2.1 \\
$\mathrm{LAS}$ & 0.34 & 28.5 & 2.9 \\
30/70 R1/LAS & 0.37 & 29.1 & 2.5 \\
50/50 R1/LAS & 0.26 & 29.4 & 2.4 \\
$70 / 30 \mathrm{R} 1 / \mathrm{LAS}$ & 0.37 & 29.8 & 2.1 \\
30/70 R2/LAS & 0.31 & 31.4 & 2.6 \\
50/50 R2/LAS & 0.26 & 32.6 & 2.5 \\
70/30 R2/LAS & 0.28 & 34.0 & 2.1
\end{tabular}

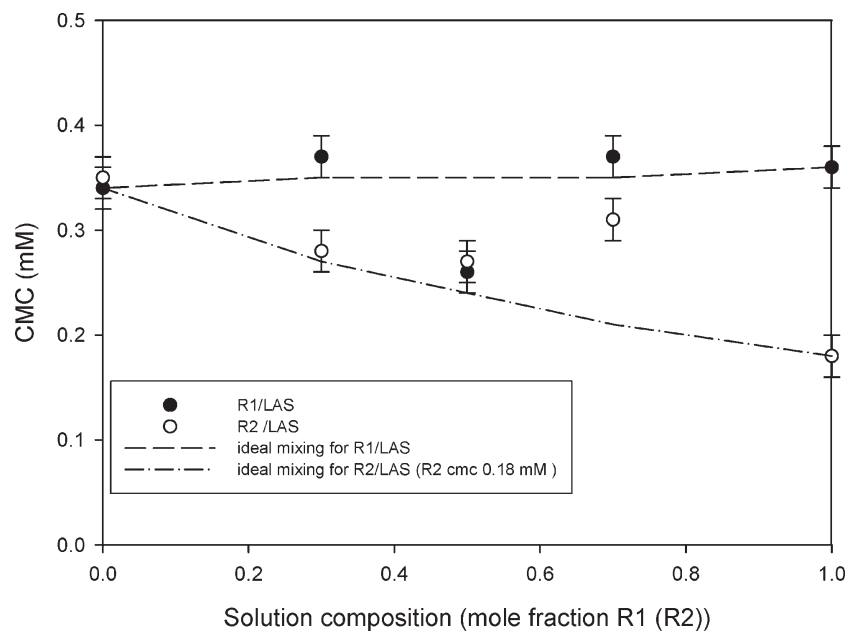

Figure 1. Variation in mixed CMC for $(\bullet)$ R1/LAS and $(O)$ R2/ LAS. The dashed lines are calculated from eq 4 assuming ideal mixing, as described in the text.

The critical micellar concentration, CMC, values (obtained from the intersection of straight line fits to the surface tension data below and above the CMC), surface tension at the CMC, and estimates of the adsorbed amount (obtained from the slope of the $\gamma$ versus $\ln C$ plots, where $\gamma$ is the surface tension and $C$ is the surfactant concentration, using the Gibbs equation with a prefactor of 1 and assuming ideal mixing) are summarized in Table 1.

The variation in CMC with solution composition for the $\mathrm{R} 1$ / LAS and R2/LAS mixtures is plotted in Figure 1. Apart from two data points which are outside the experimental error, the variation in mixed CMC with solution composition is almost linear. From Clint,${ }^{31}$ the variation in mixed CMC with composition for ideal mixing should vary as

$$
\frac{1}{C^{*}}=\frac{\alpha}{C_{1}}+\frac{(1-\alpha)}{C_{2}}
$$

where $C^{*}$ is the mixed $\mathrm{CMC}, \mathrm{C}_{1}$ and $\mathrm{C}_{2}$ are the CMCs of components 1 and 2 in a binary mixture, and $\alpha$ is the solution composition. The dashed lines in Figure 1 are calculated from eq 4, assuming ideal mixing, and are in broad agreement with the measured data. The almost linear dependence arises from the similarity of the pure R1, R2, and LAS CMC values. We will contrast this prediction of ideal mixing, based on the surface tension data, with the more direct measurement of the surface adsorption and surface composition obtained from NR in the next section.

(31) Clint, J. H. J Chem. Soc., Faraday Trans. 1 1975, 76, 1327. 
Table 2. Surfactant Component Scattering Lengths and Molecular Volumes

\begin{tabular}{lcc}
\hline surfactant & scattering length $(\AA)$ & molecular volume $\left(\AA^{3}\right)$ \\
\hline d-R1 & $4.93 \times 10^{-3}$ & 813 \\
h-R1 & $0.45 \times 10^{-3}$ & 813 \\
d-R2 & $6.13 \times 10^{-3}$ & 1052 \\
h-R2 & $0.64 \times 10^{-3}$ & 1052 \\
d-LAS & $3.48 \times 10^{-3}$ & 570 \\
h-LAS & $0.35 \times 10^{-3}$ & 570
\end{tabular}

ii. Surface Adsorption (Neutron Reflectivity). a. Binary Mixtures, R1/LAS, R2/LAS. Neutron reflectivity measurements were made at the air-solution interface for the binary mixtures of R1/LAS and R2/LAS at a fixed solution concentration of $1 \mathrm{mM}$ and for a range of different solution compositions. A further set of measurements were made for the R2/LAS mixture at a fixed solution composition of 60/40 mole ratio R2/LAS over a range of solution concentrations from 0.1 to $2 \mathrm{mM}$ (from below to above the mixed $\mathrm{CMC}$ ). The measurements were made for the two isotopic combinations, h-rhamnolipid/d-LAS and d-rhamnolipid/h-LAS, in nrw. All the reflectivity data for this sequence of measurements are consistent with a thin layer $(\sim 20 \AA)$ of surfactant of uniform composition adsorbed at the interface. The data for the h-rhamnolipid/d-LAS isotopic combination are dominated by the d-LAS contribution, and the data for the d-rhamnolipid/h-LAS are dominated by the d-rhamnolipid contribution. Consistent with the well established procedure for the analysis of such data, ${ }^{19}$ the measured reflectivity data were then fitted by comparing them (on a least-squares basis) with a calculated profile, using the optical matrix method ${ }^{32}$ to calculate the reflectivity for this simple structural model. The model parameters are the scattering length density, $\rho$, and thickness, $\tau$, of the adsorbed layer. The adsorbed amount for each component in the binary mixture can then be calculated from

$$
\rho \tau=\sum b_{1} / A_{1}+\sum b_{2} / A_{2}
$$

where $b_{i}$ and $A_{i}$ are the scattering lengths and area/molecule of each surfactant component of the binary mixture, respectively. From the reflectivity data and model fits for the two complementary isotopic combinations, dh and hd, eq 5 can be solved to obtain $A_{1}$ and $A_{2}$. Typical model parameters and derived values of adsorbed amount and surface composition are summarized in Table 3 for the R1/LAS mixture (the scattering lengths for the different surfactant components are listed in Table 2).

The parameters from the analysis of the reflectivity data for the $\mathrm{R} 2 / \mathrm{LAS}$ and R1/R2/LAS mixtures are summarized in Tables 1-5 in the Supporting Information. For the binary surfactant mixtures, the mean thickness of the mixed surfactant layer is $23 \pm 2 \AA$, which is thicker than the values previously reported for $\mathrm{R} 1$ and $\mathrm{R} 2,{ }^{14}$ but the same as measured for the R1/R2 binary mixtures. For comparison, the equivalent thickness obtained in a previous study $^{20}$ for LAS and LAS $/ \mathrm{C}_{12} \mathrm{E}_{8}$ mixtures was $19 \pm 1 \AA$. This difference in the thickness of the adsorbed layer is attributed to the longer alkyl chain length of R1 and R2 compared with the LAS- 6 isomer, where the alkyl chain is effectively divided into two by the phenyl group and the relatively large headgroups of R1 and R2.

The adsorption data for the R1/LAS mixture at a fixed surfactant concentration of $1 \mathrm{mM}$ (>CMC) are plotted in Figure 2a. As the solution composition varies from LAS rich to R1 rich, the amount of LAS at the interface decreases and the amount of R1 at

(32) Penfold, J. In Neutron, x-ray and light scattering; Lindner, P., Zemb, T., Eds.; Elsevier: North Holland, 1991 the interface increases. The total amount adsorbed (LAS + R1) decreases, from LAS rich to R1 rich, with an approximately linear dependence, reflecting the relative surface activities of the pure R1 and LAS components. Similar adsorption data for the other binary mixture, R2/LAS, are plotted in Figure 2 in the Supporting Information. In Figure $2 b$, the variation in the surface composition with solution composition is plotted for the R1/LAS mixture. Over the entire composition range measured, the surface composition is close to the solution composition. The variation in the total adsorption and in the surface composition with solution composition is broadly consistent in this case with ideal mixing between the R1 and LAS. At this surfactant concentration ( $\sim 3$ times the mixed CMC), the R1/LAS mixture shows no synergistic enhancement in the total adsorption or any strongly preferential adsorption of one of the components to the interface. The interpretation of the surface tension measurements described earlier is consistent with the NR data.

The overall trends in the adsorption data for the R2/LAS mixture (shown in Figure 2 in the Supporting Information) are qualitatively broadly similar to those for R1/LAS. However, the variation in surface composition with solution composition is markedly different, as illustrated in Figure 3a.

Although the surface tension data (see Figure 1) imply ideal mixing, the variation in the surface composition deviates substantially from the corresponding solution composition, such that for $\mathrm{R} 2$ rich solution compositions the surface is dominated by the LAS adsorption. This is similar to what has been previously reported for the adsorption of $\mathrm{R} 1 / \mathrm{R} 2$ mixtures $^{14}$ and for the nonionic surfactant mixture of $\mathrm{C}_{12} \mathrm{E}_{3} / \mathrm{C}_{12} \mathrm{E}_{8}{ }^{15,16}$ The departure from ideality reported here is more extreme than would be readily accounted for in the pseudophase approximation approach to nonideal mixing, such as regular solution theory, RST, ${ }^{33}$ using the measured values of CMC and surface pressure. However, we attribute the dominance of LAS over R2 at the surface to the steric hindrance (or packing constraints) imposed by the larger R2 headgroup, as was discussed in the context of R1/R2 $2^{14}$ and $\mathrm{C}_{12} \mathrm{E}_{3} /$ $\mathrm{C}_{12} \mathrm{E}_{8}{ }^{15,16}$ surfactant mixing.

The neutron reflectivity measurements described above were all made at a fixed surfactant concentration of $1 \mathrm{mM}$. This is on average 3 times the mixed CMC (see Table 1). A further set of measurements were made at a fixed composition (60/40 mol ratio) for the R2/LAS mixtures to evaluate the variation of the mixed adsorption with concentration. Figure $3 \mathrm{~b}$ shows the variation in the mole fraction of $\mathrm{R} 2$ at the interface for surfactant concentrations from below the $\mathrm{CMC}$ to 6 times the CMC (the corresponding adsorbed amounts are shown in Figure 3 in the Supporting Information). There is a modest variation in the surface composition with surfactant concentration, and from below the $\mathrm{CMC}$ to above the $\mathrm{CMC}$ the amount of $\mathrm{R} 2$ at the surface decreases (from a mole fraction of $\sim 0.49$ decreasing to a constant value of $\sim 0.35$, for concentrations $\sim 6$ times the mixed $\mathrm{CMC}$ ). This rather modest variation in the surface composition with surfactant concentration is expected from the small variation in the mixed CMC with composition (see Figure 1), and further reinforces the assumptions of ideal mixing in the discussion of the composition variation shown in Figure 2b. It is also consistent with trends that would be predicted from the pseudophase approximation, and in particular for RST. ${ }^{33}$ From this approach, it is expected that the micelles and surface adsorbed layer that form at the $\mathrm{CMC}$ are rich in the more surface active component (component with lowest $\mathrm{CMC}$ ), and as the solution concentration increases, the surface/ micelle compositions will evolve toward the solution composition.

(33) Holland, P. M. Colloids Surf., A 1986, 19, 171. 
Table 3. Key Model Parameters from Analysis of Reflectivity Data for R1/LAS Mixture at a Surfactant Concentration of 1 mM

\begin{tabular}{|c|c|c|c|c|c|c|c|}
\hline $\begin{array}{l}\text { solution composition } \\
\text { (mole fraction R1) }\end{array}$ & $\begin{array}{c}\text { contrast } \\
\text { combination }\end{array}$ & $\begin{array}{c}\tau \\
( \pm 1 \AA)\end{array}$ & $\left( \pm 0.2 \times 10^{-6} \AA^{-2}\right)$ & $\stackrel{A}{A}\left(\AA^{2}\right)$ & $\left( \pm 0.1 \times 10^{-10} \mathrm{~mol} \mathrm{~cm}^{-2}\right)$ & $\Gamma_{\text {total }}$ & $\begin{array}{l}\text { surface composition } \\
( \pm 0.02 \text { mol fraction } \mathrm{R} 1)\end{array}$ \\
\hline \multirow[t]{2}{*}{0.7} & $\mathrm{dh}$ & 23 & 2.2 & $96 \pm 4$ & 1.73 & \multirow[t]{2}{*}{2.9} & \multirow[t]{2}{*}{0.59} \\
\hline & hd & 30 & 0.8 & $141 \pm 8$ & 1.18 & & \\
\hline \multirow[t]{2}{*}{0.6} & $\mathrm{dh}$ & 23 & 2.0 & $111 \pm 6$ & 1.5 & \multirow[t]{2}{*}{3.0} & \multirow[t]{2}{*}{0.51} \\
\hline & hd & 23 & 1.3 & $114 \pm 6$ & 1.46 & & \\
\hline \multirow[t]{2}{*}{0.5} & $\mathrm{dh}$ & 24 & 1.8 & $119 \pm 7$ & 1.39 & \multirow[t]{2}{*}{3.0} & \multirow[t]{2}{*}{0.46} \\
\hline & hd & 25 & 1.4 & $102 \pm 6$ & 1.64 & & \\
\hline \multirow[t]{2}{*}{0.4} & $\mathrm{dh}$ & 25 & 1.3 & $129 \pm 7$ & 1.29 & \multirow[t]{2}{*}{3.1} & \multirow[t]{2}{*}{0.41} \\
\hline & hd & 21 & 1.8 & $90 \pm 4$ & 1.84 & & \\
\hline \multirow[t]{2}{*}{0.3} & $\mathrm{dh}$ & 23 & 1.2 & $173 \pm 10$ & 0.96 & \multirow[t]{2}{*}{3.2} & \multirow[t]{2}{*}{0.3} \\
\hline & hd & 21 & 2.2 & $76 \pm 3$ & 2.19 & & \\
\hline \multirow[t]{2}{*}{0.2} & $\mathrm{dh}$ & 23 & 1.0 & $211 \pm 10$ & 0.79 & \multirow[t]{2}{*}{3.6} & \multirow[t]{2}{*}{0.22} \\
\hline & hd & 23 & 2.4 & $62 \pm 2$ & 2.68 & & \\
\hline
\end{tabular}

(a)

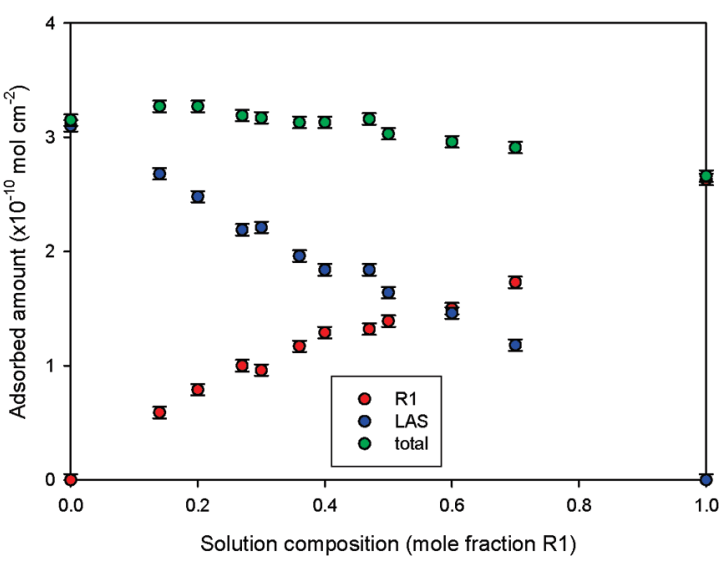

(b)

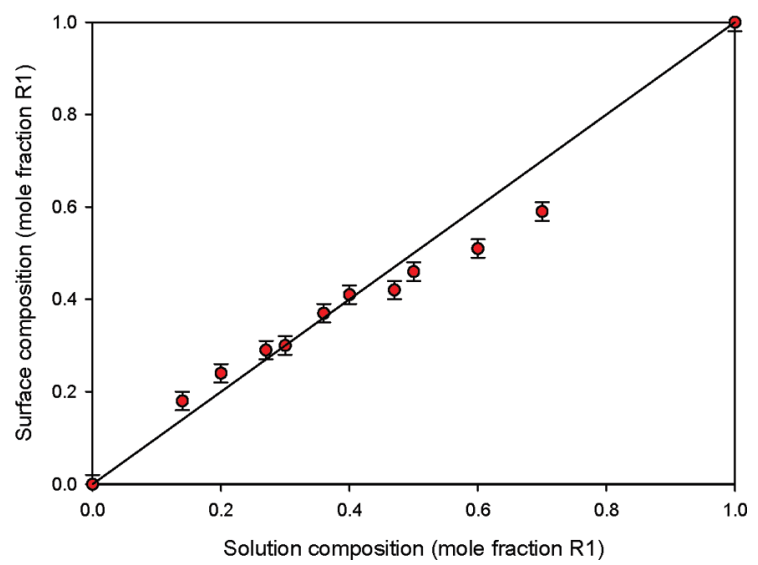

Figure 2. (a) R1/LAS adsorption and (b) R1/LAS surface composition for R1/LAS mixture at $1 \mathrm{mM}$ and $\mathrm{pH}$ 9. See legend for details.

These trends have been observed in a number of different surfactant mixtures by SANS and NR. ${ }^{15,34-37}$ This is what is broadly observed here, except as was discussed earlier, because of

(34) Staples, E.; Thompson, L.; Tucker, I.; Penfold, J.; Thomas, R. K.; Lu, J. R. Langmuir 1993, 9, 1651.

(35) Penfold, J.; Staples, E.; Thompson, L.; Tucker, I.; Hines, J.; Thomas, R. K.; Lu, J. R. Langmuir 1995, 11, 2596.

(36) Penfold, J.; Staples, E.; Cummins, P.; Tucker, I.; Thompson, L; Thomas,

R. K.; Simister, E. A.; Lu, J. R. J. Chem. Soc., Faraday Trans. 1996, 92, 1773.

(37) Hines, J. D.; Thomas, R. K.; Garrett, P. R.; Rennie, G. K.; Penfold, J. J. Phys. Chem. B 1997, 101, 9215.
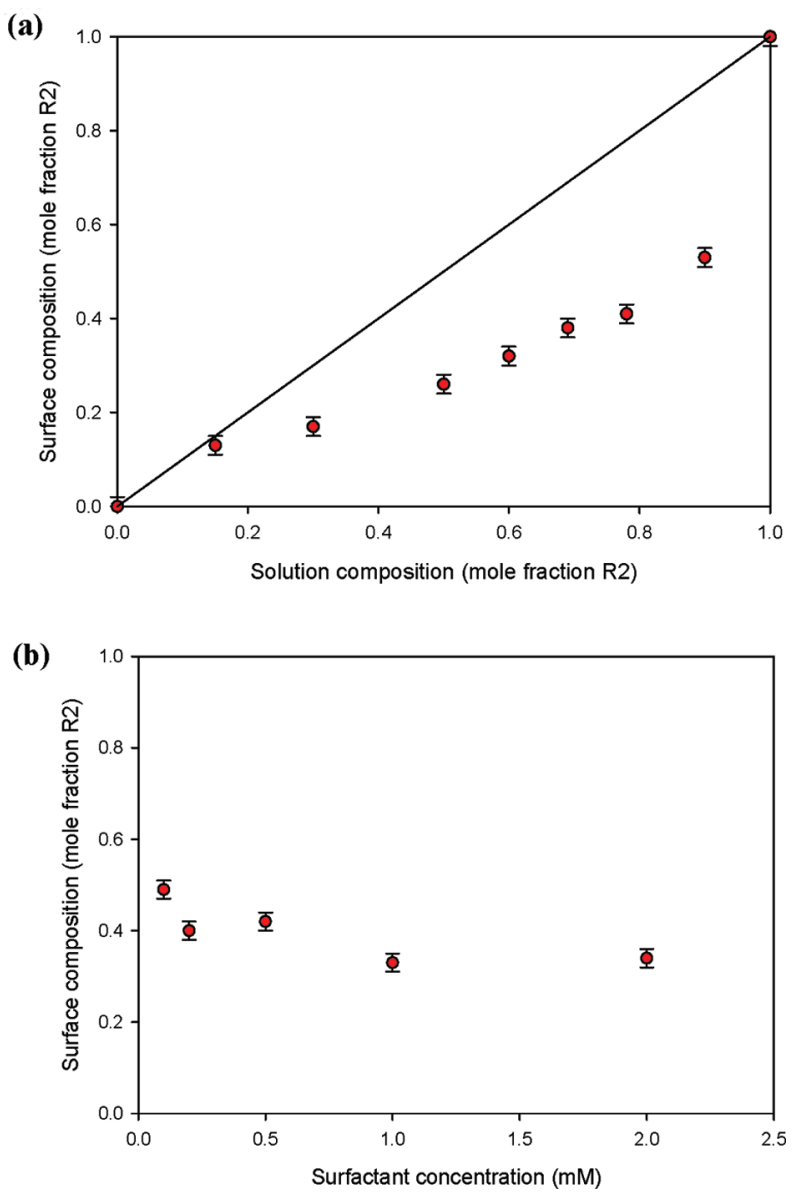

Figure 3. (a) R2/LAS surface composition versus solution composition at a surfactant concentration of $1 \mathrm{mM}$ and (b) R2/LAS surface composition versus surfactant conecntration at fixed solution composition of $60 / 40 \mathrm{~mol}$ ratio $\mathrm{R} 2 / \mathrm{LAS}$.

the packing constraints of the larger R2 dirhamnose headgroup, the surface composition does not eventually evolve to the solution composition. That is, for concentrations $\gg \mathrm{CMC}$, the surface remains dominated by the LAS adsorption, even though R2 has a lower CMC than LAS. The lower CMC would normally imply an intrinsically greater surface activity, as observed in the general trend in the surface composition with increasing solution concentration. 


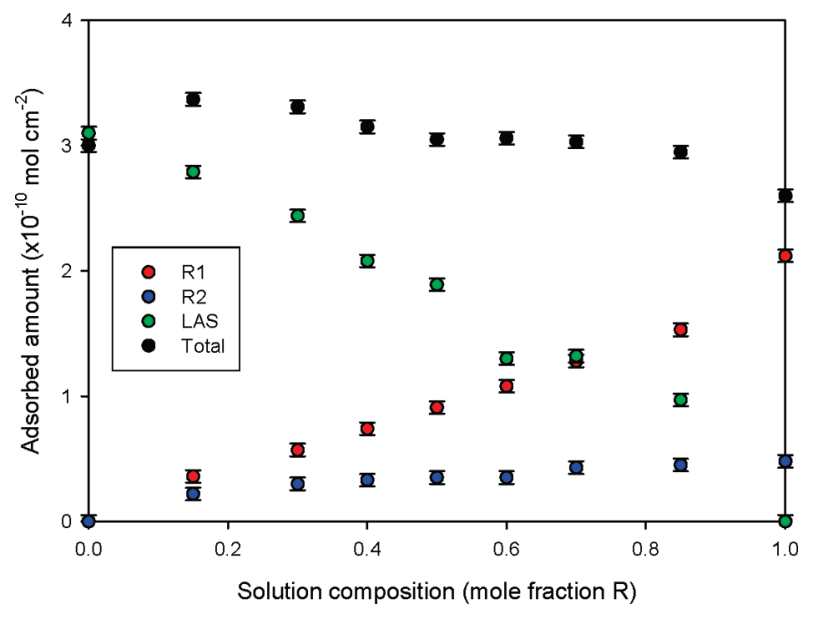

Figure 4. Adsorption of R1, R2, and LAS and total adsorption versus solution composition (mole fraction of rhamnolipid) for R1/R2 2:1/LAS ternary mixture at $1 \mathrm{mM}$. See legend for details.

b. Ternary Mixtures, R1/R2/LAS. Neutron reflectivity measurements were also made for the R1/R2/LAS ternary mixtures at a fixed surfactant concentration of $1 \mathrm{mM}$ and for three different R1/R2 compositions (2:1, 1:1, and 1:2). Here the measurements were made for the three different contrasts d-R1/ h-R2/h-LAS, h-R1/d-R2/h-LAS, and h-R1/h-R2/d-LAS. By extending eq 5 to incorporate a third component, the adsorbed amount for each of the three components can be obtained. The adsorption data for the R1/R2 (2:1)/LAS mixture are shown in Figure 4.

Similar data for R1/R2 compositions of $1: 1$ and $1: 2$ are illustrated in Figures 4 and 5 in the Supporting Information. The associated model parameters for all the ternary mixtures are summarized in Tables 3-5 in the Supporting Information. The data shown in Figure 4 are typical of those obtained for all three of the R1/R2 compositions studied. For solution compositions progressively richer in rhamnolipid $(\mathrm{R} 1+\mathrm{R} 2)$, the amount of $\mathrm{R} 1$ and $\mathrm{R} 2$ at the surface increases, with the increase in R1 being more pronounced. In conjunction with this, the amount of LAS at the surface decreases. However, at rhamnolipid/LAS compositions away from $100 \%$ rhamnolipid or $100 \%$ LAS, the total adsorption is greater than that of the rhamnolipid or LAS alone. This implies some synergy in the ternary adsorption, and we will return to this important point later in the discussion.

In Figure 5, the variation in surface composition with solution composition for the individual components of the R1/R2/LAS ternary mixtures is plotted for R1/R2 compositions of 2:1, 1:1, and 1:2. Although in detail quantitatively different, the overall trends are broadly similar for all three of the $\mathrm{R} 1 / \mathrm{R} 2$ compositions studied. That is, the surface behavior of the R1/R2/LAS ternary mixtures broadly reflects the trends observed in the binary mixtures of R1/R2, R1/LAS, and R2/LAS. For all three R1/R2 compositions, the LAS component dominates the surface over most of the solution composition range studied and has a surface composition which is higher than its equivalent solution composition. In contrast, the contribution of the $\mathrm{R} 1$ component is close to its solution composition, such that for the 2:1 R1/R2 mixture the R1 surface mole fraction is only slightly but systematically lower than its solution mole fraction, for the 1:1 R1/R2 mixture the surface and solution R1 mole fractions are identical, and for the $1: 2 \mathrm{R} 1 / \mathrm{R} 2$ mixture the surface mole fraction of $\mathrm{R} 1$ is slightly and systematically higher than the corresponding solution mole fraction. For all three R1/R2 solution compositions, the R2 component is partially depleted from the surface compared with the (a) 2:1 R1/R2

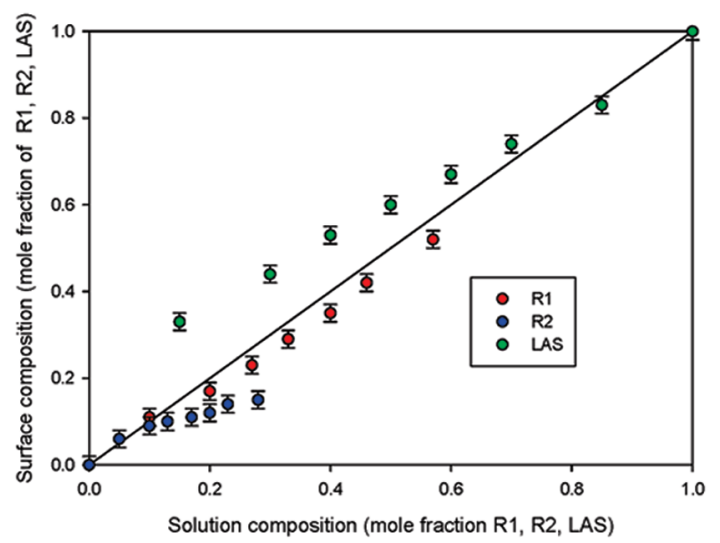

(b)1:1 R1/R2

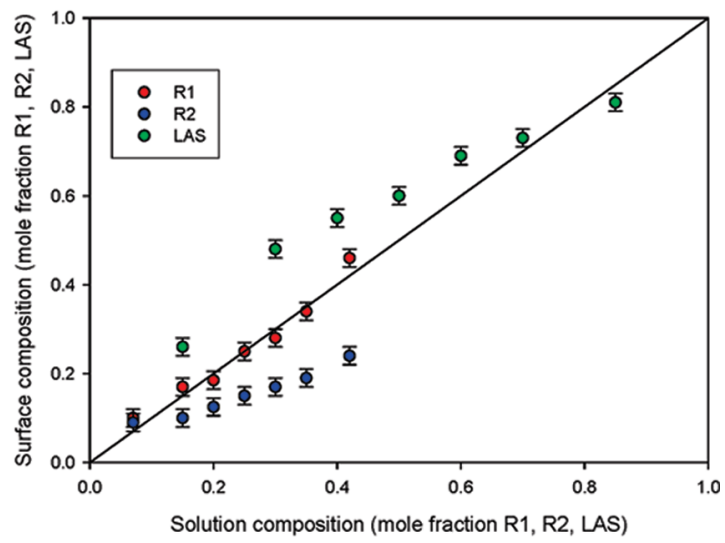

(c) $1: 2 \mathrm{R} 1 / \mathrm{R} 2$

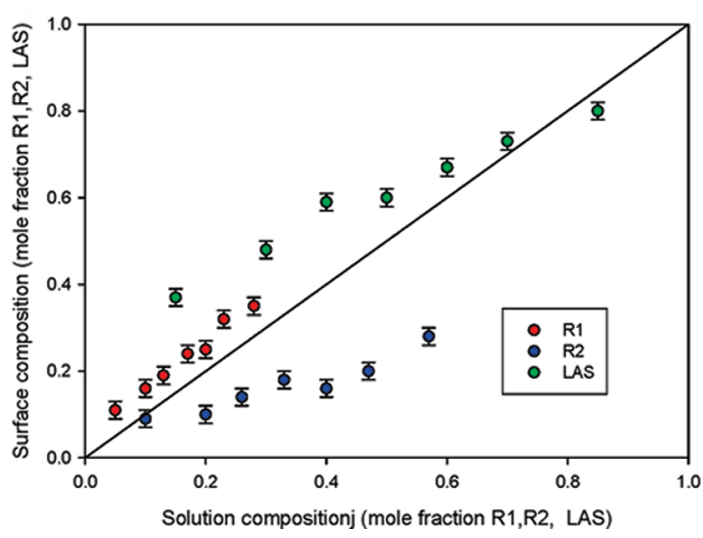

Figure 5. R1/R2/LAS surface composition versus solution composition for different R1/R2 compositions (a) 2:1 R1/R2, (b) $1: 1$ R1/R2, and (c) 1:2 R1/R2. See legend for details.

solution composition. Hence, the LAS component dominates the adsorption of the ternary mixtures, R1 competes favorably with the LAS, and R2 competes less favorably with either the LAS or $\mathrm{R} 1$ components. The dominance of the LAS adsorption is further demonstrated in Figure 6, where the surface mole fraction of LAS is plotted against the LAS/rhamnolipid solution composition. The similarity of the three curves for R1/R2/LAS (for R1/R2 compositions of 2:1, 1:1, and 1:2) also illustrates the dominance of the LAS component, and demonstrates that the composition of the $\mathrm{R} 1 / \mathrm{R} 2$ mixtures at the surface adjusts to a roughly constant rhamnolipid contribution independent of the solution R1/R2 composition. 


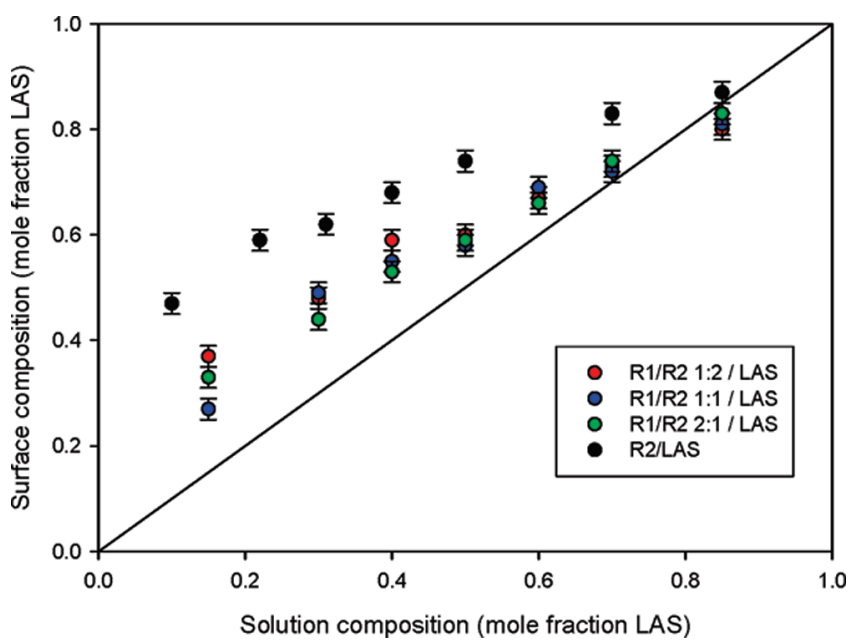

Figure 6. Surface composition versus solution composition (mol \% LAS) for rhamnolipid/LAS mixtures (1:2, 1:1, and 2:1, R1/R2 compositions) and R2/LAS at a surfactant concentration of $1 \mathrm{mM}$. See legend for details.

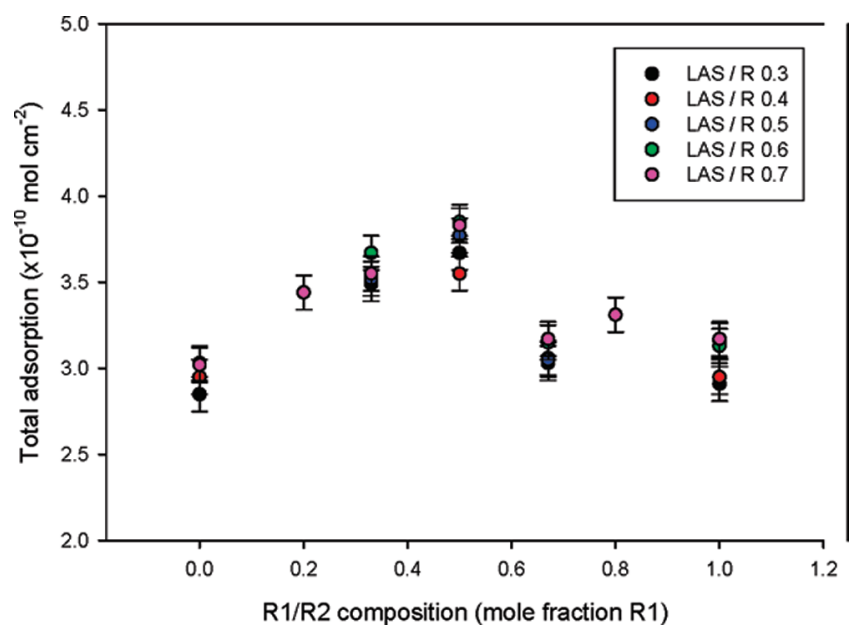

Figure 7. Total adsorption for R1/R2/LAS mixtures for different $\mathrm{R} / \mathrm{LAS}$ ratios, at $1 \mathrm{mM}$ surfactant concentration. See legend for details.

A major feature of the adsorption behavior of the ternary $\mathrm{R} 1 / \mathrm{R} 2 / \mathrm{LAS}$ mixtures is the variation in the total adsorption $(\mathrm{R} 1+\mathrm{R} 2+\mathrm{LAS})$ with $\mathrm{R} 1 / \mathrm{R} 2$ and rhamnolipid/LAS compositions. Compared with the pure individual R1, R2, and LAS components and the binary $\mathrm{R} 1 / \mathrm{R} 2, \mathrm{R} 1 / \mathrm{LAS}$, and $\mathrm{R} 2 / \mathrm{LAS}$ mixtures, the total adsorption shows a significant enhancement in the total adsorption, and this is illustrated in Figure 7.

In Figure 7, the total adsorption is plotted as a function of the R1/R2 composition for different LAS/rhamnolipid compositions. The adsorption data show a clear maximum in the adsorption at an equimolar R1/R2 composition, which is, within error, broadly independent of the LAS/rhamnolipid composition. A broadly similar trend is illustrated in Figure 6 in the Supporting Information, where the total adsorption is plotted as a function of LAS/rhamnolipid solution composition for different R1/R2 compositions. The associated adsorbed amounts are summarized in Table 6 in the Supporting Information. Compared with the adsorbed amounts of the pure R1, R2, and LAS components (2.9, 1.9 , and $3.1 \times 10^{-10} \mathrm{~mol} \mathrm{~cm}^{-2}$ respectively), the maximum adsorption for the R1/R2/LAS ternary mixture is $\sim 3.9 \times 10^{-10} \mathrm{~mol} \mathrm{~cm}^{-2}$, a fractional increase of $1.33,2.02$, and 1.24 compared with the adsorption of the corresponding pure components.

c. Discussion. Most experimental and theoretical studies on surfactant mixing have focused on binary mixtures. ${ }^{17,18,38,39}$ However, the pseudophase approximation ${ }^{40}$ approach to nonideal mixing and the regular solution approximation ${ }^{33}$ are implicitly multicomponent and can be extended to three components in a straightforward way. ${ }^{41}$ Shiloach and Blankschtein ${ }^{42}$ have also extended their molecular-thermodynamic theory approach to consider the nonideal mixing of ternary surfactant mixtures. Some recent studies based on surface tension measurements have used different aspects of the pseudophase approximation to probe the behavior of a range of different ternary surfactant mixtures. ${ }^{43-46}$ However, they rely entirely upon theoretical treatments for their interpretation and provide no direct information about the adsorption above the CMC. The potential difficulties of this approach and the need for more direct measurements have been highlighted elsewhere. ${ }^{19}$ It has now been extensively demonstrated that NR can provide that adsorption information directly, both above and below the CMC. ${ }^{19}$ This has been done for a range of different binary surfactant mixtures ${ }^{19,34-37}$ and has in particular highlighted some of the difficulties and deficiencies associated with applying the pseudophase approximation. ${ }^{37}$

NR has also been applied to the study of the adsorption of multicomponent surfactant mixtures. ${ }^{41,47}$ Staples et al. ${ }^{47}$ studied the adsorption of mixed nonionic/SDS surfactant mixtures at the air-water interface, exploring the role of dodecanol and the evolution of the nonionic/SDS adsorption above the CMC in ternary mixtures. Hines et al. ${ }^{41}$ studied the adsorption (below the $\mathrm{CMC}$ ) of the ternary surfactant mixture of SDS/betaine/maltoside, comparing the results from surface tension and NR. In particular, they compared the surface tension derived area per molecule, using a multicomponent extension of the pseudophase approximation for nonideal mixing in the ternary mixture, with the directly measured values from NR. The failure of the pseudophase approximation approach here was associated with the failure to predict the correct mixing behavior in the binary $\mathrm{SDS} /$ betaine mixture. This was in turn attributed to an excess entropy of mixing term arising from hydration changes on mixing. However, they were able to demonstrate that, by using interaction parameters derived from the NR data, the ternary mixing behavior can be predicted on the basis of the mixing behavior of the binary mixtures.

These observations by Hines et al. ${ }^{41}$ are broadly consistent with the observations reported here for the rhamnolipid/LAS surfactant mixtures. That is, the general trends observed in the ternary R1/R2/LAS mixtures are consistent with the observations for the R1/R2, ${ }^{14}$ R1/LAS, and R2/LAS mixtures. However, the variations in surface adsorption (as discussed earlier) are not quantitatively consistent with the pseudophase approximation approach

(38) Hill, R. M. In Mixed surfactant systems; Ogino, K., Abe, M., Eds.; Surfactant Science Series; Marcel Dekker: New York, 1993; Vol. 46, Chapt. 11

(39) Holland, P. M.; Rubingh, D. N., Eds. Mixed surfactant systems; ACS Symposium Series; American Chemical Society: Washington, DC, 1992; Vol. 501.

(40) Rubnigh, D. N. In Solution Chemistry of surfactants; Mittal, K. L., Ed.; Marcel Dekker: New York, 1979; Vol. 1, p 337.

(41) Hines, J. D.; Thomas, R. K.; Garrett, P. R.; Rennie, G. K.; Penfold, J. J. Phys. Chem. B 1998, 102, 9708.

(42) Shiloach, A.; Blankschtein, D. Langmuir 1998, 14, 4105.

(43) Ghoulam, M. B.; Moatadid, N.; Graciaa, A.; Lachaise, J.; Manon, G.; Schechter, R. S. J. Colloid Interface Sci. 1998, 200, 74.

(44) Dar, A. A.; Rather, G. M.; Ghosh, S.; Das, A. R. J. Colloid Interface Sci. 2008, 322, 572 .

(45) Ghosh, S. J. Colloid Interface Sci. 2001, 244, 128

(46) Szymczyk, K.; Janczuk, B. Langmuir 2010, 26, 2491.

(47) Staples, E.; Thompson, L.; Tucker, I.; Penfold, J. Langmuir 1994, 10, 4136. 
based on the surface tension data, and hence, a more detailed quantitative thermodynamic evaluation has not been made.

A significant difference between the behavior of the binary mixtures of $\mathrm{R} 1 / \mathrm{R} 2^{14}$ and of $\mathrm{R} 1 / \mathrm{LAS}$ and $\mathrm{R} 2 / \mathrm{LAS}$ reported here compared with the ternary $\mathrm{R} 1 / \mathrm{R} 2 / \mathrm{LAS}$ mixtures is that for the binary mixtures no synergy in the total adsorption is observed. However, as demonstrated in Figure 7, the ternary mixtures give rise to a synergistic enhancement of the total adsorption. An insight into the mechanism for this synergistic enhancement is illustrated in Figure 6. The surface composition, expressed in mol \% LAS, as a function of solution composition (mol \% LAS) is plotted for the R2/LAS and the R1/R2/LAS (for R1/R2 of 1:2, $1: 1$, and $2: 1$ compositions) mixtures. For all the mixtures, the LAS adsorption dominates the surface adsorption over the entire composition range, from rhamnolipid to LAS rich solution compositions. For the three different R1/R2 compositions, the departure from ideal mixing in the adsorption behavior of the $\mathrm{R} 1 / \mathrm{R} 2 / \mathrm{LAS}$ mixtures is essentially independent of the R1/R2 composition. However, for the R2/LAS mixture, the departure from ideality, in favor of the LAS adsorption, is significantly more pronounced. Furthermore, the preferential adsorption at the surface in favor of R1 for the R1/R2 mixture ${ }^{14}$ is very similar to that presented here for R2/LAS. Hence, it seems that in the ternary mixture the headgroup interactions and packing constraints associated with R1, R2, and LAS partially mitigate the unfavorable interaction/packing observed in the binary $\mathrm{R} 1 / \mathrm{R} 2$ and R2/LAS mixtures. Thus, it is probably the reduction in that unfavorable interaction that is responsible for the synergistic enhancement in the total adsorption observed in the ternary mixtures. It is evident from the data that both $\mathrm{R} 1$ and $\mathrm{R} 2$ are required and that the maximum effect with LAS occurs at a 50/50 mole ratio of $\mathrm{R} 1$ and $\mathrm{R} 2$

iii. Solution Self-Assembly. a. $\operatorname{Binary}(R 1 / L A S, R 2 / L A S)$ and Ternary $(R 1 / R 2 / L A S)$ Mixtures. The solution self-assembly properties and phase behavior of the R1/LAS, R2/LAS, and $\mathrm{R} 1 / \mathrm{R} 2 / \mathrm{LAS}$ mixtures at relatively low surfactant concentrations $(<100 \mathrm{mM})$ and in buffer at $\mathrm{pH} 9$ have been determined using SANS and complemented by some DLS measurements.

Measurements were made for the R1/LAS and R2/LAS mixtures over a wide composition range and in the concentration range of $20-100 \mathrm{mM}$, a regime where SANS has previously proved to be an appropriate technique to quantify directly the phase behavior in such systems. ${ }^{20,48}$ Some typical SANS data for the R2/LAS and R1/LAS mixtures, which illustrate the key features and trends, are shown in Figure 8.

The SANS data in Figure 8a show the evolution in the scattering for the R2/LAS mixture as the solution composition varies from R2 to LAS rich compositions at a fixed surfactant concentration of $50 \mathrm{mM}$. The data illustrated in the figure are for R2/LAS mole ratios of 100/0,80/20, 10/90, and 0/100 (the plots are shifted vertically as indicated in the caption for clarity) and show the evolution in microstructure from micellar to micellar/ lamellar coexistence and ultimately a planar (lamellar) structure. In Figure 8b, a complementary sequence of SANS data for the $\mathrm{R} 1 / \mathrm{LAS}$ mixtures is presented. Here the data presented are for a fixed solution composition, R1/LAS mole ratio of 50/50, and for solutions of increasing concentration, at 20,50,60, and $80 \mathrm{mM}$ (the different plots are again shifted vertically for improved clarity of presentation).

For the R2/LAS mixture (Figure 8a), the SANS data for the R2 rich solution compositions $(80 / 20$ and $100 / 0)$ are consistent with

(48) Tucker, I.; Penfold, J.; Thomas, R. K.; Tildesley, D. J. Langmuir 2009, 25, 3924
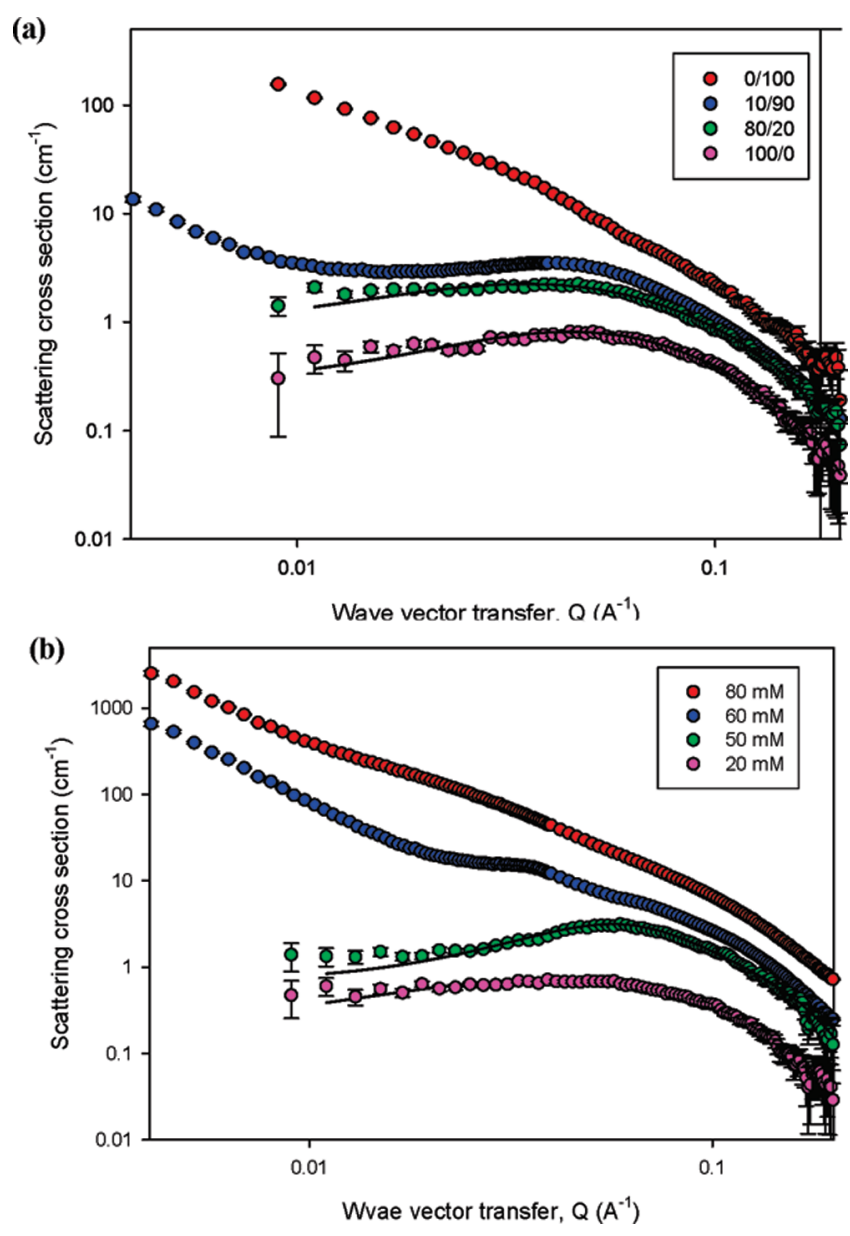

Figure 8. SANS data for (a) $50 \mathrm{mM} \mathrm{R} 2 / \mathrm{LAS}$ for R2/LAS compositions of $0 / 100,10 / 90,80 / 20$, and $100 / 0$, and (b) $50 / 50 \mathrm{~mol}$ ratio $\mathrm{R} 1 / \mathrm{LAS}$ at 20, 50, 60, and $80 \mathrm{mM}$. The solid lines are model fits as described in the text and for the model parameters summarized in Table 4 and in the Supporting Information. The different curves are shifted vertically for clarity. See legend for details.

relatively small globular micelles. In contrast, the SANS data for the LAS rich compositions $(0 / 100)$ have a $Q^{-2}$ dependence, and this is consistent with the formation of predominantly planar structures. The lack of pronounced features in the $Q^{-2}$ dependence of the scattering is consistent with the formation of relatively flexible membrane structures and hence large polydisperse unilamellar, ulv, or bilamellar, blv, vesicles. The SANS data for the solution composition of 10/90 has a different form. The scattering at high $Q\left(>0.02 \AA^{-1}\right)$ is consistent with small globular micelles, whereas the upturn in the scattering at low $Q$ $\left(<0.01 \AA^{-1}\right)$ implies significant growth. We attribute this to the coexistence of micelles and planar (vesicle) structures, where in this case the micellar contribution to the scattering dominates. The micellar scattering (for $80 / 20$ and $100 / 0$ solution R2/LAS compositions) shows an almost flat $Q$ dependence in the scattering at low $Q$, and this is consistent with relatively weakly interacting nonionic surfactant micelles, as was previously reported for R2 and R1/R2 mixed micelles. ${ }^{14}$ The SANS data for the 10/90 mole ratio R2/LAS mixture exhibits a broad peak in the micellar scattering contribution at high $Q$, and this arises from the intermicellar interaction/correlations due to the screened Coulombic interaction between the more highly charged LAS rich mixed micelles.

For the R1/LAS mixture (Figure 8b), a slightly different evolution in the form of the SANS scattering data is observed. 
Table 4. Micelle Model Parameters for 50 mM R2/LAS

\begin{tabular}{ccccccc}
\hline $\begin{array}{c}\text { solution } \\
\text { composition } \\
(\mathrm{R} 2 / \mathrm{LAS})\end{array}$ & $\begin{array}{c}\text { aggregation } \\
\text { number, } \\
v( \pm 4)\end{array}$ & $\begin{array}{c}\text { surface } \\
\text { charge, } \\
z( \pm 0.5)\end{array}$ & $\begin{array}{c}\mathrm{R} 1 \\
( \pm 1 \AA)\end{array}$ & $\begin{array}{c}\mathrm{R} 2 \\
( \pm 1 \AA)\end{array}$ & $\begin{array}{c}\text { ext } \\
( \pm 0.5)\end{array}$ & $\begin{array}{c}\text { ee } \\
( \pm 0.1)\end{array}$ \\
\hline $10 / 90$ & 134 & 15 & 14.5 & 17.5 & 1.12 & 4.7 \\
$20 / 80$ & 105 & 5 & 14.5 & 17.5 & 1.11 & 3.8 \\
$40 / 60$ & 82 & 4 & 13.0 & 16.5 & 1.0 & 4.1 \\
$80 / 20$ & 55 & 4 & 12.0 & 15.5 & 0.89 & 3.8 \\
$90 / 10$ & 34 & 2 & 11.5 & 15.0 & 0.83 & 2.9
\end{tabular}

At the lower surfactant concentrations $(20,50 \mathrm{mM})$, the scattering is in the form of relatively small globular micelles. At the higher surfactant concentration $(50 \mathrm{mM})$, the contribution to the scattering from the intermicellar interactions is evident. At the higher surfactant concentrations $(60,80 \mathrm{mM})$, the scattering has a predominantly $Q^{-2}$ dependence. For the higher surfactant concentration $(80 \mathrm{mM})$, the scattering is now entirely $Q^{-2}$ and is associated with planar (lamellar) structures. Consistent with the previous discussion for the R2/LAS mixtures, the scattering arises from large polydisperse vesicles, ulv/blv. At a surfactant concentration of $60 \mathrm{mM}$, the scattering is consistent with lamellar/planar coexistence, but with the lamellar/planar contribution dominating the scattering.

A quantitative analysis of the micellar regions and the predominantly micellar parts of the micellar/lamellar coexistence regions has been made using a standard model for interacting globular micelles ${ }^{27}$ as described in the experimental section by eqs 2 and 3 . The micellar component to the scattering in the mixed micellar/lamellar regions was analyzed by restricting the analysis to data for $Q$ values $>0.02 \AA^{-1}$, in order to minimize the effects due to the contribution of more planar structures at lower $Q$. A core + shell form factor was used to describe the micelle geometry, in which molecular constraints were incorporated. The inner core, radius $r_{1}$, containing the alkyl chains, was constrained to have a maximum dimension of the fully extended alkyl chain length, $l_{\mathrm{c}}$, which was taken here to be $14.0 \AA$ for R1, R2 and as $12.9 \AA$ for LAS. This was modified by an additional factor, ext, which allows for additional packing constraints, some alkyl chain/headgroup mixing, and uncertainties in the actual alkyl chain/headgroup interface, and in this study ext varies between 0.85 and 1.20. The outer radius $r_{2}$ is defined by the outer shell which is determined by space filling the shell volume with the headgroups and their associated hydration. For aggregation numbers, $v$, greater than can accommodated in a molecular volume defined by a radius, $l_{\mathrm{c}} \times$ ext, growth is accommodated by allowing the micelle shape to become elliptical and the ellipticity was defined by the parameter ee. Hence, the overall dimensions are $r_{2}, r_{2}$, ee $\times r_{2}$. In this study, the aggregation number is such that the globular micelles are elliptical with ee $>2.0$. For the R1/LAS, R2/LAS, and R1/R2/ LAS mixtures, ideal mixing in the aggregates was assumed. From known molecular volumes, scattering lengths (see Table 2), and the total surfactant concentration, all the parameters required for eqs 2 and 3 can be calculated. The refinable model parameters are then $v$, the surface charge, $z$ (which along with the micelle number density, $n$, defines the strength of the intermicellar interaction), and ext.

Typical model parameters from the analysis of the $50 \mathrm{mM} \mathrm{R} 2 /$ LAS SANS micelle data (for R2/LAS solution compositions from $10 / 90$ to $100 / 0$ mol ratio) are presented in Table 4.

For the R2/LAS mixture and for the ternary R1/R2/LAS mixtures (at R1/R2 composition ratios of $1: 2$ and 1:1), the micellar and micellar/lamellar regions where a quantitative analysis of the micellar structure is possible and is sufficiently extensive that the evolution in the micelle structure with solution (a)

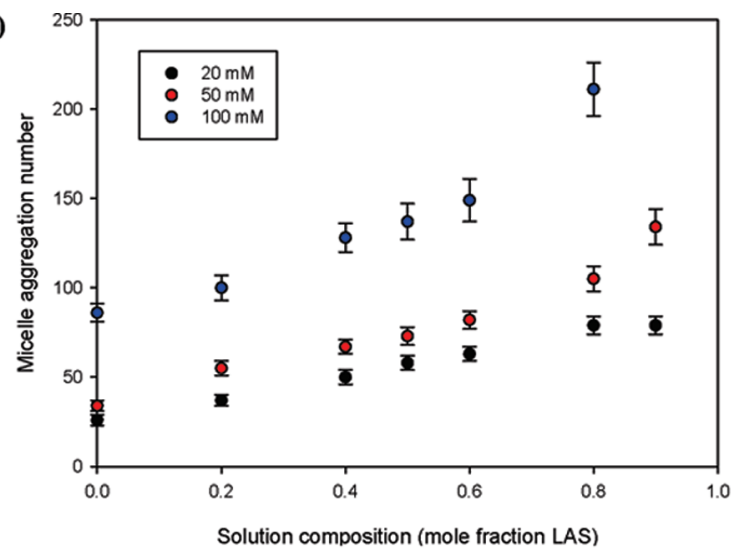

(b)

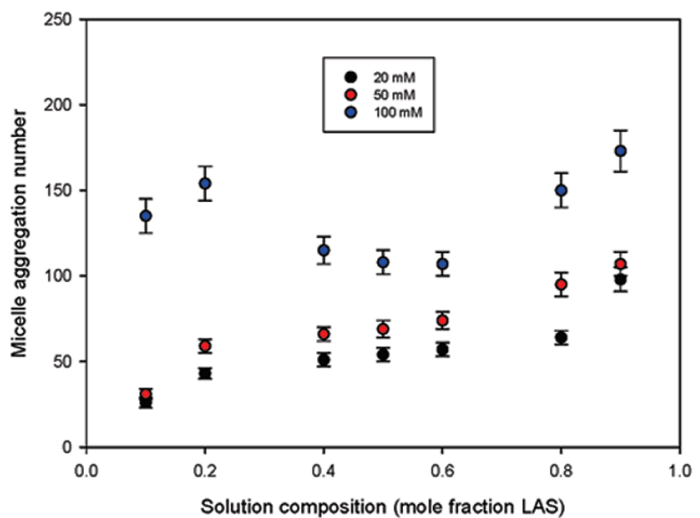

(c)

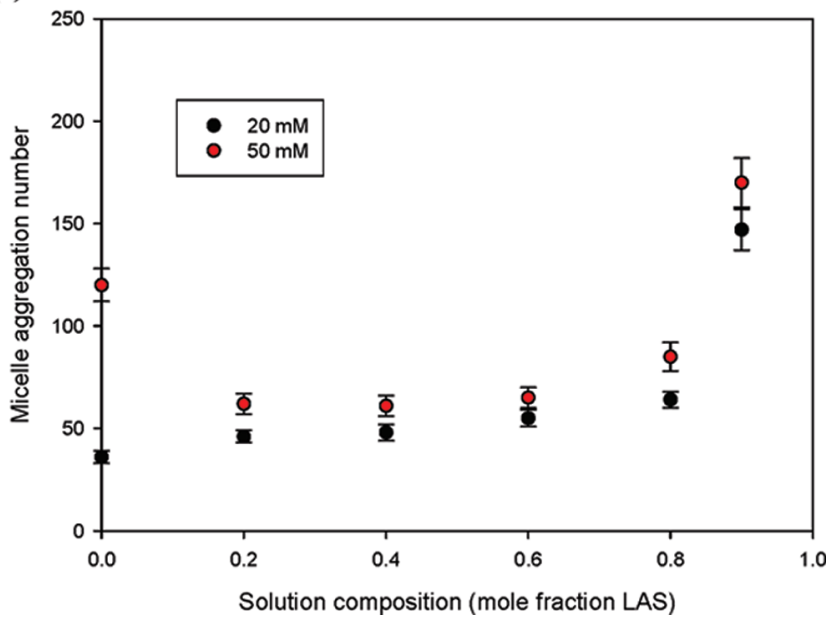

Figure 9. Variation in micelle aggregation number for (a) R2/ LAS, (b) R1/R2 (1:2) /LAS, and (c) R1/R2 (1:1)/LAS at different surfactant concentrations, 20,50 , and $100 \mathrm{mM}$, as indicated in the legend.

concentration and composition can be correlated are shown in Figure 9. A summary of all the derived micelle aggregation numbers (where a quantitative analysis has been possible) are listed in Table 7 in the Supporting Information.

In Figure 9a, the variation in micelle aggregation number for the R2/LAS mixture at solution concentrations of 20, 50, and $100 \mathrm{mM}$ is shown. With increasing mole fraction of LAS, the aggregation number increases, and the increase is more substantial as the total surfactant concentration increases. This is consistent with the LAS preferring a lower curvature environment compared with R2 and with the LAS surfactant being closer to a micellar/lamellar transition in the absence of cosurfactant. ${ }^{20}$ 
(a)

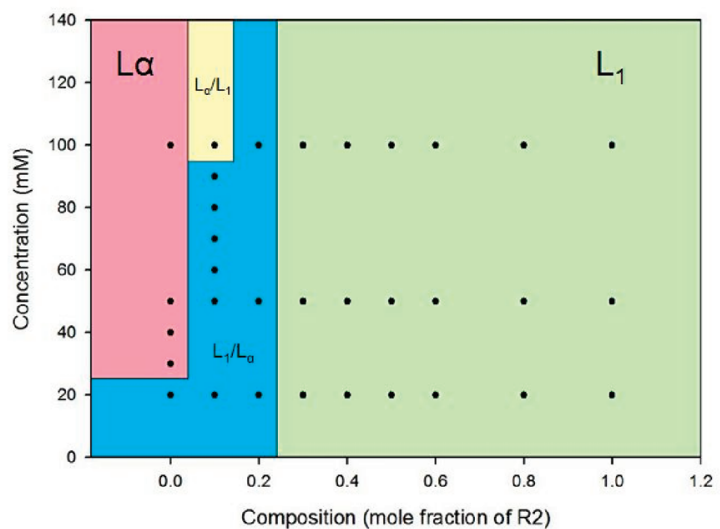

(b)

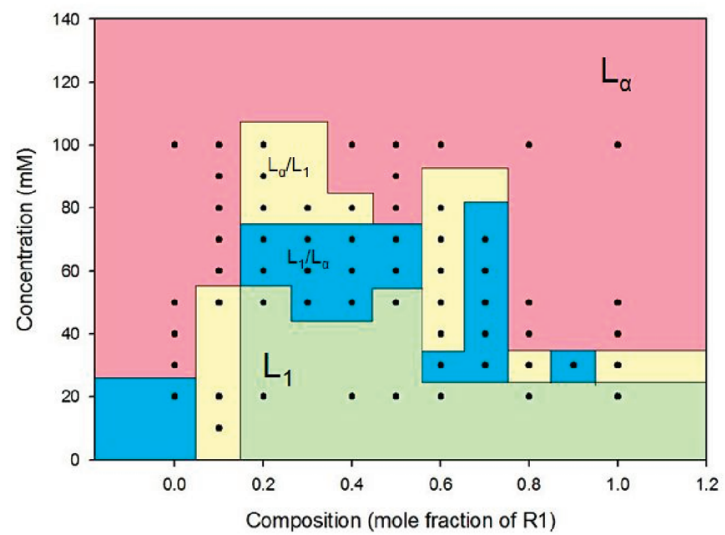

(e)

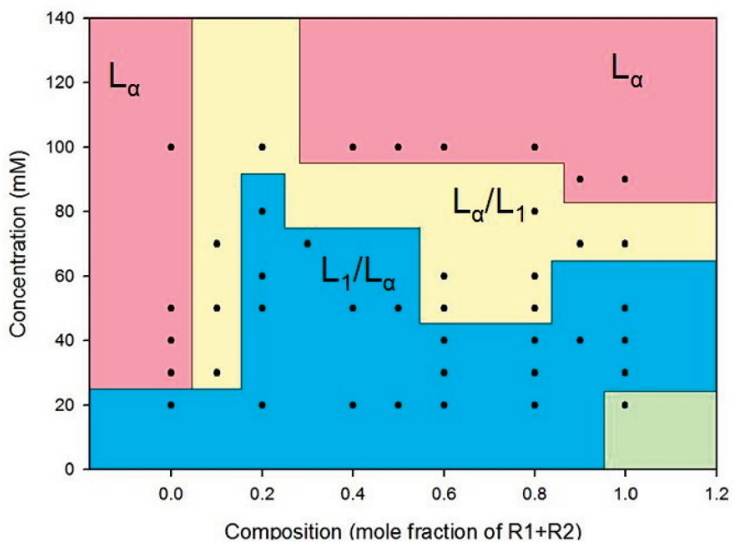

(c)

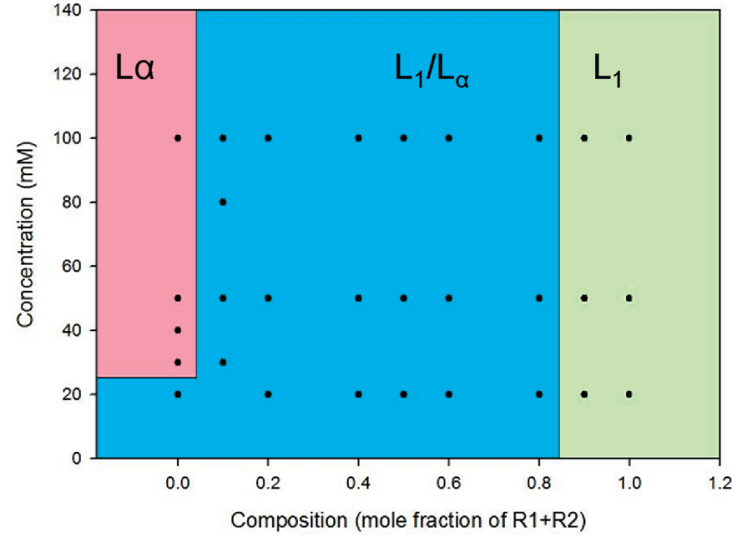

(d)

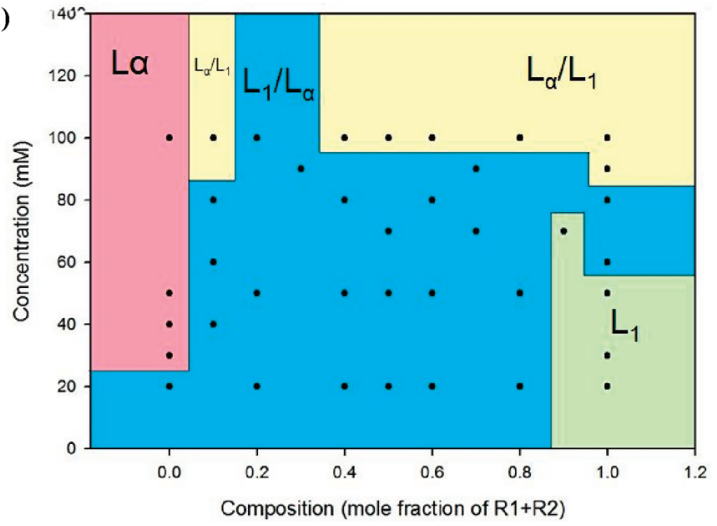

Figure 10. Phase behavior for (a) R2/LAS, (b) R1/LAS, (c) R1/R2 (1:2)/LAS, (d) R1/R2 (1:1)/LAS, and (e) R1/R2 (2:1)/LAS, derived from SANS and DLS measurements.

The corresponding data for the R1/LAS mixture are not plotted (a summary of the variation in micelle aggregation numbers obtained can be found in Table 7 in the Supporting Information) because a quantitative analysis of the micelles was only possible over a relatively limited range of compositions and concentrations. This further illustrates the dominance of the preferred lower curvature of both R1 and LAS in determining the resultant microstructure, which is now predominantly planar.

A more complex variation in the aggregation number with surfactant composition and concentration is exhibited for the R1/ R2/LAS mixtures (see Figure $9 \mathrm{~b}$ and $\mathrm{c}$ ). For both R1/R2 compositions plotted (1:2 and 1:1), the same general trend in the variation of the aggregation number with solution compositions is observed at the lower surfactant concentrations (20, 50 $\mathrm{mM})$. For the higher surfactant concentration $(100 \mathrm{mM})$, the influence of the R1 component, which has a greater preference for structures with a lower mean curvature, ${ }^{14}$ is evident. For R1/R2 (1:2), this tendency of R1 for lower curvature structures, along with the tendency of LAS to prefer an environment of lower curvature, results in an increase in the aggregation number for both LAS and rhamnolipid rich compositions. This is also observed for R1/R2 (1:1) at a surfactant concentration of $50 \mathrm{mM}$. For R1/R2 (1:1), there is no equivalent data at $100 \mathrm{mM}$ as the microstructure is already predominantly planar (lamellar) over most of the composition range. Hence, at intermediate compositions, the higher preferred curvature associated with R2 results in this more complex evolution of the micelle aggregation number. The corresponding data for R1/R2 (2:1) are also not plotted here. Apart from the data at $20 \mathrm{mM}$, where there is only a modest change in the aggregation number with composition (see Table 7 in the Supporting Information), the extent of the data where a quantitative analysis of the micelles scattering could be 
made is relatively limited. This again demonstrates the dominance of the preference for planar structures dictated by R1 and LAS.

The general variations in the mixed surfactant microstructure for the R1/LAS, R2/LAS, and R1/R2/LAS mixtures are broadly consistent with those previously reported for R1, R2, and the $\mathrm{R} 1 / \mathrm{R} 2$ mixture $^{14}$ and for LAS and LAS/nonionic surfactant mixtures. ${ }^{20}$ However, a direct correlation with the data for LAS and LAS/nonionic mixtures in the literature ${ }^{20}$ is not as relevant because those measurements were not made in buffer at $\mathrm{pH} 9$.

b. Solution Phase Behavior. From the overall SANS scattering patterns and trends with both surfactant concentration and composition (for the different binary and ternary mixtures), it has been possible to determine the phase behavior for the different rhamnolipid/LAS mixtures, and these are shown in Figure 10. Some light scattering measurements were made in order to clarify the boundaries of the mixed phase region.

In Figure 10a, the phase diagram for the R2/LAS mixture is presented and represents the simplest of those determined. For R2/LAS compositions up to $\sim 30 / 70$ mole ratio, the mixed surfactant microstructure is entirely micellar $\left(\mathrm{L}_{1}\right)$. For solution compositions richer in LAS (20/80 and 10/90), micellar/lamellar coexistence $\left(\mathrm{L}_{1} / \mathrm{L}_{\alpha}\right)$ is observed, but the micellar component is still the dominant structure and the main contributor to the scattering. The micellar/lamellar coexistence regions are subdivided into two separate regions, $\mathrm{L}_{1} / \mathrm{L}_{\alpha}$ and $\mathrm{L}_{\alpha} / \mathrm{L}_{1}$, where the micellar and lamellar contributions to the scattering dominate. Here $\mathrm{L}_{1} / \mathrm{L}_{\alpha}$ is defined as the region where $\mathrm{L}_{1}$ dominates sufficiently that a quantitative analysis of that phase is possible. It is only for the pure LAS and for R2/LAS at 10/90 mole ratio at the higher surfactant concentration that the more planar structures associated with the LAS dominate the microstructure. Hence, it is evident that the high preferred curvature associated with R2 (due to its large dirhamnose headgroup) dominates the R2/LAS phase behavior. This is broadly similar to the observation for LAS/ $\mathrm{C}_{12} \mathrm{E}_{8}$ mixtures ${ }^{20}$ at low surfactant concentrations in the absence and in the presence of $\mathrm{CaCl}_{2}$.

For the R1/LAS mixture (see Figure 10b), a different phase behavior exists. It is dominated by the tendency of both the LAS and R1 to prefer more planar structures; apart from the lower surfactant concentration where micellar structures still exist, there is a greater predominance of planar structures.

In Figure 10c-e, the phase behavior for the ternary mixtures of $\mathrm{R} 1 / \mathrm{R} 2 / \mathrm{LAS}$ for $\mathrm{R} 1 / \mathrm{R} 2$ composition ratios of $1: 2,1: 1$, and $2: 1$ is plotted. For the R1/R2 composition of 1:2, the overall phase behavior is relatively similar to that for R2/LAS (see Figure 10a). The microstructure is micellar $\left(\mathrm{L}_{1}\right)$ for $\mathrm{R} 1 / \mathrm{R} 2$ rich compositions. It is only lamellar $\left(\mathrm{L}_{\alpha}\right)$ for the pure LAS concentrations, and there are no further $\mathrm{L}_{\alpha}$ or $\mathrm{L}_{\alpha} / \mathrm{L}_{1}$ regions. Over much of the composition range, the microstructure is mixed $\mathrm{L}_{1} / \mathrm{L}_{\alpha}$. Hence, it is evident here that the high preferred curvature associated with $\mathrm{R} 2$ still dominates the mixed phase behavior, although the $\mathrm{R} 1$ component does induce a wider $\mathrm{L}_{1} / \mathrm{L}_{\alpha}$ coexistence region compared with the $\mathrm{R} 2 /$ LAS binary mixture. This coexistence region is restricted to a much narrower region of LAS rich compositions in the R2/LAS mixture. The phase behavior for the R1/R2 1:1 composition with LAS (see Figure 10d) is broadly similar to that for the 1:2 R1/R2 composition, except that the higher $\mathrm{R} 1$ concentration leads to a greater $\mathrm{L}_{\alpha} / \mathrm{L}_{1}$ coexistence region at the higher surfactant concentrations. Finally, the phase behavior for the R1/R2 2:1 composition with LAS (Figure 10e) reflects the greater R1 concentration present. As such, the R1/R2 (2:1)/LAS phase behavior is much closer to that observed for R1/LAS (Figure 10b); that is, the greater tendency of R1 and LAS to form planar structures dominates the mixed phase behavior.

These general trends from micellar to planar structures, with regions of micellar/lamellar coexistence, have been reported in other related systems. ${ }^{20,48}$ As discussed earlier, there are similarities between the R2/LAS phase behavior and that reported for $\mathrm{LAS} / \mathrm{C}_{12} \mathrm{E}_{8} \cdot{ }^{20}$ The R1/LAS and $\mathrm{R} 1 / \mathrm{R} 2$ (for $\mathrm{R} 1 / \mathrm{R} 2$ ratios of $2: 1$ )/ LAS mixtures exhibit a phase behavior which is more reminiscent of that observed for the dialkyl chain cationic/nonionic mixtures of DHDAB $/ \mathrm{C}_{12} \mathrm{E}_{6}$ and DHDAB $/ \mathrm{C}_{12} \mathrm{E}_{12}{ }^{48}$ The notable difference is that for the DHDAB/nonionic mixtures the lower preferred curvature of the DHDAB is more dominant in the phase behavior at the lower surfactant concentrations than is observed in the R1/LAS mixture. However, the R1/R2 (for R1/R2 ratios of $1: 2$ and 1:1)/LAS mixtures have a much broader micellar/lamellar coexistence region, and this is associated with the competing curvature requirements of $\mathrm{R} 1$ and $\mathrm{R} 2$.

\section{Summary}

i. Surface Adsorption. Neutron reflectivity and surface tension have been used to probe the surface adsorption of the rhamnolipids R1 and R2 with the anionic surfactant LAS at the air-water interface. In the binary R1/LAS mixtures, the surface behavior is close to ideal. In contrast, in the binary R2/LAS mixture, the surface is dominated by the LAS adsorption at a surfactant concentration well above the CMC. This arises predominantly from the packing constraints imposed by the larger dirhamnose headgroup of R2. In the ternary R1/R2/LAS mixtures, the same overall trends are observed and the LAS is preferentially adsorbed compared with $\mathrm{R} 1$ and $\mathrm{R} 2$ regardless of the $\mathrm{R} 1 / \mathrm{R} 2$ composition. In contrast to the binary mixtures, the ternary mixtures show a significant enhancement in the total adsorption compared with the pure components.

ii. Solution Self-Assembly. The corresponding solution selfassembly and associated phase behavior at relatively low surfactant concentrations $(<100 \mathrm{mM})$ show trends which reflect the relative preferred curvatures of $\mathrm{R} 1, \mathrm{R} 2$, and LAS. In the R1/LAS mixture, the predominant structure is planar (lamellar) in the form of vesicles, ulv or blv. In the R2/LAS mixture, the predominant structure is relatively small globular micelles. In the ternary R1/R2/LAS mixtures, the evolution in the structure from micelles to lamellar (ulv, blv) with composition and concentration is more complex but can be rationalized in terms of the competition between the preferred relative curvatures of the three components.

Acknowledgment. We acknowledge the provision of neutron beam time at ISIS (SURF, LOQ) and at the ILL (D11, D22) and the invaluable assistance of the Instrument Scientists at ISIS and the ILL. The support of Unilever and the dti Technology programme for the project is acknowledged.

Supporting Information Available: Additional plots of surface tension data and of data on adsorbed amounts, and tabulated model parameters from analysis of NR and SANS data, not included in the main text. This material is available free of charge via the Internet at http://pubs.acs.org. 